\title{
Euterpe oleracea Mart. (Açai) Supplementation Attenuates Acute Doxorubicin-Induced Cardiotoxicity in Rats
}

\author{
Lívia Maria Beraldo Simões Mathias ${ }^{a}$ Patricia Helena Correa Alegre ${ }^{a}$ \\ Isadora de Oliveira Fernandes dos Santos ${ }^{a}$ Tatiana Bachiega ${ }^{a}$ \\ Amanda Menezes Figueiredo ${ }^{a}$ Fernanda Chiuso-Minicuccia \\ Ana Angélica Fernandes ${ }^{\mathrm{b}}$ Silméia Garcia Zanatti Bazan ${ }^{\mathrm{a}}$ \\ Marcos Ferreira Minicuccia Paula Schmidt Azevedo ${ }^{a}$ Marina Politi Okoshia \\ Leonardo Antonio Mamede Zornoffa Sergio Alberto Rupp Paiva ${ }^{a}$ \\ Bertha Furlan Polegato
}

aMedical School, São Paulo State University (Unesp), Botucatu, Brazil, bInstitute of Biosciences, São Paulo State University (Unesp), Botucatu, Brazil

\section{Key Words}

Oxidative stress $•$ Apoptosis $•$ Matrix metalloproteinase-2 2 Cardiac function

\begin{abstract}
Background/Aims: Doxorubicin, a chemotherapy drug used successfully for years, could induce cardiotoxicity. Euterpe oleracea Mart. (açai) is a fruit high in antioxidant properties. The aim of this study was to evaluate doxorubicin-induced cardiotoxicity prevention after açai administration. Methods: A total of 64 male Wistar rats were allocated into 4 groups: control (C), açai (A), doxorubicin (D) and açai-doxorubicin (DA). Rats received regular chow (C and D groups) or chow supplemented with açai 5\% (A and DA groups) for 4 weeks. Subsequently, rats received doxorubicin $20 \mathrm{mg} / \mathrm{kg}$ ( $D$ and DA groups) or saline (C and $A$ groups). Euthanasia was performed 48 hours after doxorubicin injection. Left ventricular function was evaluated by echocardiography in vivo and by isolated heart study ex vivo. Oxidative stress, myocardial metabolism and nitric oxide metabolite were evaluated by spectrophotometry, MMP-2 activity by zymography and caspase -3 and $\mathrm{Bcl}-2$ protein expression by Western blot. Results: Doxorubicin induced decreases in body weight, food and water ingestion. We observed decreases in left ventricular fractional shortening in rats treated with doxorubicin. Additionally, the same rats showed lower $+\mathrm{dP} / \mathrm{dt}$ and $-\mathrm{dP} / \mathrm{dt}$ during isolated heart study than those who did not receive doxorubicin. Doxorubicin injection increased caspase-3 protein expression, myocardium lipid hydroperoxide concentration, MMP-2 activity, phosphofructokinase and lactate dehydrogenase activity, and decreased $\beta$-hydroxyacyl-CoA dehydrogenase, pyruvate dehydrogenase, citrate synthase, complex I, complex II and ATP synthase activity
\end{abstract}




\section{Cellular Physiology Cell Physiol Biochem 2019;53:388-399

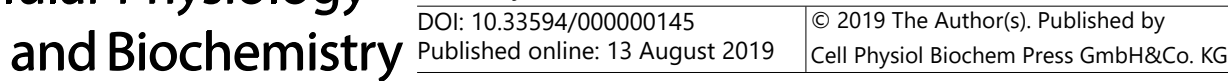 \\ Mathias et al.: Açai Attenuates Doxorubicin Cardiotoxicity}

in myocardium. Açai supplementation improved left ventricular fractional shortening, decreased myocardium lipid hydroperoxide concentration, MMP-2 activity, and improved $\beta$-hydroxyacyl-CoA dehydrogenase, phosphofructokinase, citrate synthase, complex II and ATP synthase enzymatic activities. We did not observe differences in nitric oxide metabolite concentrations between groups. Conclusion: Doxorubicin induced left ventricular dysfunction, increases in oxidative stress, changes in myocardium metabolism and MMP-2 activation. Açai supplementation was able to prevent these alterations.

(C) 2019 The Author(s). Published by

Cell Physiol Biochem Press GmbH\&Co. KG

\section{Introduction}

Doxorubicin is a chemotherapy drug extract from Streptomyces peucetius fungi and has been used to treat solid tumors and hematologic cancers since the 60s. Nausea, vomiting, alopecia and neutropenia are very common side effects. However, cardiotoxicity is the most serious side effect of doxorubicin treatment and could limit its use in treatment. Cardiotoxicity has several clinical presentations that depend on symptom onset [1].

Chronic cardiotoxicity is the most studied form. The symptoms start weeks or months after treatment and manifest as heart failure and dilated cardiomyopathy. Acute cardiotoxicity is hard to diagnose since it has a less specific clinical presentation. Approximately $11 \%$ of patients can develop acute cardiotoxicity hours or days after treatment [2,3]. Despite these differences in clinical presentation, there is evidence that myocardial damage, including ventricular dysfunction, starts early after doxorubicin administration [4-6].

Many mechanisms are involved in the pathophysiology of doxorubicin-induced cardiotoxicity, and they are not completely understood. Increases in oxidative stress seem to be a cornerstone of myocardial injury [7]. It was recently discovered that increases in reactive oxygen species generation depend on inhibition of topoisomerase 2-beta by anthracyclines [8-10]. An oxidative environment is a potent activator of matrix metalloproteinase (MMP) [11]. Indeed, MMP activation is an early event in doxorubicin-induced cardiotoxicity [5, $6,12,13]$. In addition, doxorubicin could induce changes in myocardial metabolism and mitochondrial dysfunction which is another important source of reactive species [7, 14]. Doxorubicin administration in rats decreased myocardial lipid metabolism, increased glucose metabolism and decreased enzymatic complex activity of the phosphorylative mitochondrial chain [6], with decreased ATP production [14]. In addition, doxorubicin elevated sympathetic tone, activated the renin-angiotensin-aldosterone system, increased vasopressin and deregulated NO release [7], thereby contributing to vasoconstriction and left ventricular dysfunction.

Considering cardiotoxicity severity can limit the effectiveness of doxorubicin administration and treatment, it is important to discover new strategies or substances that attenuate doxorubicin mediated cardiac injury. Thus, antioxidant rich substances could be of use.

Açai (Euterpe oleracea Mart.) is a Brazilian fruit from palms of the Arecaceae family. They are rich in fatty acids, including oleic and linoleic acid. In addition, açai has an elevated content of anthocyanins, phenolic compounds with high antioxidant effects [517]. Experimental studies have shown that açai has an anti-proliferative effect in neoplastic cells $[18,19]$, a nitric oxide-mediated vasodilatory effect in mesenteric circulation [20] and was able to reduce genotoxicity induced by doxorubicin [21]. However, the effect of açai in doxorubicin-induced cardiotoxicity has not been studied before.

The aim of study was to evaluate the influence of açai on morphological and functional cardiac alterations, oxidative stress, myocardium metabolism, apoptosis and MMP-2 activity in acute doxorubicin-induced cardiotoxicity in rats. 


\section{Cellular Physiology Cell Physiol Biochem 2019;53:388-399 \begin{tabular}{ll|l}
\cline { 2 - 3 } DOI: 10.33594/000000145 & ( 2019 The Author(s). Published by \\
\cline { 2 - 4 }
\end{tabular} and Biochemistry Published online: 13 August 2019 Cell Physiol Biochem Press GmbH\&Co. KG \\ Mathias et al.: Açai Attenuates Doxorubicin Cardiotoxicity}

\section{Materials and Methods}

\section{Study design}

This study was previously approved by the local Ethics Committee (protocol number: 1098/2014). Sixty-four male Wistar rats, weighing between 250 and $300 \mathrm{~g}$, were kept in a controlled environment with a 12-hour light-dark cycle at $23^{\circ} \pm 2^{\circ} \mathrm{C}$, and free access to food and water. Rats were allocated to 4 groups (16 rats in each group): control (C), doxorubicin (D), açai (A) and doxorubicin/açai (DA). Groups C and D received regular chow and groups A and DA received chow supplemented with açai 5\% [19] for 4 weeks. Food and water ingestion were measured during the experiment. Subsequently, rats in D and DA groups received a single intraperitoneal (IP) injection of doxorubicin $(20 \mathrm{mg} / \mathrm{kg})[5,6,22]$ and rats in C and A groups received an equivalent volume IP injection of saline. Groups $D$ and DA continued to receive açai in the 48 hours between doxorubicin injection and euthanasia. Forty-eight hours after doxorubicin administration, echocardiogram was performed on all animals, followed by euthanasia and isolated heart study. The isolated heart study was performed in 8 rats per group anesthetized with sodium thiopental $(80 \mathrm{mg} / \mathrm{kg}$, IP). Rats subjected to isolated heart study were different from rats used to collect hearts for biochemical analyses, as the retrograde perfusion in isolated heart study could interfere with these analyses. Euthanasia was performed by heart excision after thiopental injection $(120 \mathrm{mg} / \mathrm{kg}$, IP). Hearts were washed in fresh saline, dissected, weighed and stored at $-80^{\circ} \mathrm{C}$ until biochemical analysis. Blood was collected, centrifuged and sera stored at $-80^{\circ} \mathrm{C}$.

\section{Preparation of diet with açai}

All the commercial açai pulp (Icefruit ${ }^{\circledR}$ ) used in preparing the diet was homogenized and stored at $-80^{\circ} \mathrm{C}$. Pulp was mixed with ground chow Nuvilab (Nuvital ${ }^{\circledR}$ ), homogenized, pelleted and stored at $-20^{\circ} \mathrm{C}$ until administration. The mixture contained 5\% açai, as per Fragoso et al. [19].

\section{Cardiac function evaluation in vivo: echocardiogram}

Doppler-echocardiograms were performed by one examiner who was blinded to condition. Rats were anesthetized with ketamine $(50 \mathrm{mg} / \mathrm{kg}$, IP) and xylazine $(1 \mathrm{mg} / \mathrm{kg}$, IP), and exams were performed using a Vivid S6 system (General Electric Medical Systems, Israel) with a 5.0 - $11.5 \mathrm{MHz}$ multifrequency transducer. Measurements were obtained in M-mode. We evaluated the left atrium, left ventricle and aorta diameters, and interventricular septum and left posterior wall thicknesses. Systolic function was analyzed by left ventricular fractional shortening. Diastolic function was analyzed by $\mathrm{E}$ and $\mathrm{A}$ waves, E/A ratio, E wave deceleration time, and isovolumetric relaxation time (absolute value and corrected by heart rate).

\section{Cardiac function evaluation in vitro: isolated heart study}

The isolated heart study was performed as previously described [5]. Briefly, rats were subjected to sternotomy, and the aorta was dissected and cannulated. Subsequently, retrograde perfusion was started with modified Krebs-Henseleit solution ( $\mathrm{NaCl} 118.5 \mathrm{mM} / \mathrm{L} ; \mathrm{KCl} 4.69 \mathrm{mM} / \mathrm{L} ; \mathrm{CaCl}_{2} 2.52 \mathrm{mM} / \mathrm{L} ; \mathrm{MgSO}_{4} 1.16$ $\mathrm{mM} / \mathrm{L} ; \mathrm{KH}_{2} \mathrm{PO}_{4} 1.18 \mathrm{mM} / \mathrm{L}$; glucose $5.50 \mathrm{mM} / \mathrm{L} ; \mathrm{NaHCO}_{3} 25.88 \mathrm{mM} / \mathrm{L}$ and mannitol $8 \mathrm{mM} / \mathrm{L}$ ). The solution was kept at $37^{\circ} \mathrm{C}$, with a perfusion pressure of $75 \mathrm{mmHg}$ and a controlled $\mathrm{O}_{2}$ concentration. Hearts were transferred to the isolated heart study apparatus (Hugo Sachs Elektronik - March-Hugstetten, Germany). A latex balloon connected to a pressure transducer was inserted in the left ventricular cavity. The volume inside the balloon was increased to change diastolic pressure from 0 to $25 \mathrm{mmHg}$. After each volume variation, we recorded diastolic and systolic left ventricular pressures, maximum left ventricular pressure decrease rate $(-\mathrm{dP} / \mathrm{dt})$ and maximum left ventricular pressure development rate $(+\mathrm{dP} / \mathrm{dt})$.

\section{Oxidative stress}

Samples of left ventricular tissue $(100 \mathrm{mg})$ were homogenized in sodium phosphate buffer $\mathrm{pH}=7.4$ $(0.01 \mathrm{M})$ and then centrifuged at $12,000 \mathrm{rpm}$ for 30 minutes at $-4^{\circ} \mathrm{C}$. The supernatants were used to determine lipid hydroperoxide concentration by spectrophotometry, as a marker of oxidative damage [23]. Antioxidant enzymatic activity was determined by spectrophotometry in the same supernatants. We evaluated glutathione peroxidase (E.C.1.11.1.9.), superoxide dismutase (E.C.1.15.1.1.) and catalase (EC.1.11.1.6.) activity as per previously described methods [24, 25]. All reagents were obtained from SigmaAldrich (Saint Louis, USA). 


\section{Cellular Physiology Cell Physiol Biochem 2019;53:388-399

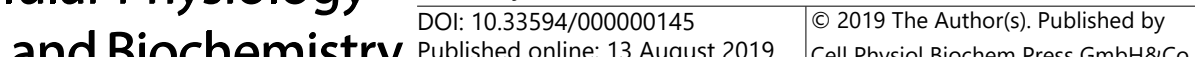 \\ Published online: 13 August 2019 Cell Physiol Biochem Press GmbH\&Co. KG \\ Mathias et al:: Açai Attenuates Doxorubicin Cardiotoxicity}

\section{Myocardial metabolism}

All enzymatic activities in myocardium were determined by spectrophotometry. Approximately $100 \mathrm{mg}$ of left ventricular tissue was homogenized in sodium phosphate buffer $\mathrm{pH}=7.0(0.1 \mathrm{M})$ and then centrifuged at $12,000 \mathrm{rpm}$ for 30 minutes at $-4^{\circ} \mathrm{C}$. Supernatants were used to determine $\beta$-hydroxyacyl coenzyme- $\mathrm{A}$ dehydrogenase (E.C.1.1.1.35), phosphofructokinase, lactate dehydrogenase (E.C.1.1.1.27), pyruvate dehydrogenase (E.C.1.2.4.1) and citrate synthase (E.C.4.1.3.7) activities [26]. Complex I (E.C.1.6.5.3), complex II (E.C.1.3.5.1) and ATP synthase (E.C.3.6.3.14) activities (enzymes belong to mitochondrial respiratory chain) were measured in the pellet [27]. The pellet was resuspended in sodium phosphate buffer $(0.1 \mathrm{M})$ with sucrose $250 \mathrm{mM}$ and ethylenediamine tetraacetic acid $2 \mathrm{mM}$. Readings were performed on a $\mu$ Quant microplate reader (Bio-Tec Instruments, Winooski, VT, USA). All reagents were obtained from Sigma-Aldrich.

\section{MMP-2 activity: zymography}

Approximately $30 \mathrm{mg}$ of left ventricular muscle was added to extraction buffer (Tris $50 \mathrm{mM} \mathrm{pH} \mathrm{7.4,} \mathrm{NaCl}$ $0.2 \mathrm{M}$, Triton $\mathrm{X} 0.1 \%$ and $\mathrm{CaCl}_{2} 10 \mathrm{mM}$ ), crushed and centrifuged. Protein was quantified in supernatants by the Bradford method. Samples (10 $\mu$ g of protein) were diluted in sample buffer (Tris $0.5 \mathrm{M} \mathrm{pH} 6.8$, glycerol $50 \%$ and bromophenol blue $0.05 \%$ ) and electrophoresis was performed on polyacrylamide $8 \%$ and gelatin $1 \%$ gels. The run was performed at $110 \mathrm{~V}$ in a Bio-Rad mini-protean system in the presence of running buffer (Tris-Glycine-SDS pH 8.3). After running, the gels were washed with Triton X-100 2.5\% and Tris-HCl $50 \mathrm{mM} \mathrm{pH}$ 8.4. The gels were incubated for 17 hours at $37^{\circ} \mathrm{C}$ with continuous agitation (buffer tris- $\mathrm{HCl} 50$ $\mathrm{mM} \mathrm{pH}$ 8.4, $\mathrm{CaCl}_{2} 500 \mathrm{mM}$ ). The gels were stained with Coomassie brilliant blue $2.5 \%$ and discolored by methanol 30\% and acetic acid 10\%. The gels were photographed by ImageQuant LAS (General Electrics) and analyzed by Gel-Pro 3.2 (Media Cybernetics Rockville, USA). The same control sample was included in each gel to normalize the results. MMP-2 position in the gels was confirmed by recombinant rat/mouse MMP-2 standard (R\&D System).

\section{Expression of proteins involved in apoptosis: Western blot}

Left ventricular muscle $(100 \mathrm{mg})$ was added to extraction buffer, homogenized and centrifuged. Supernatants were collected and total amount of protein was quantified by the Bradford method. Electrophoresis was performed in acrylamide gels and proteins were transferred to nitrocellulose membranes, which were incubated in 5\% skimmed milk. Subsequently, membranes were incubated with primary antibodies for caspase-3 (rabbit monoclonal IgG, Cell Signaling Technology, MA, USA) and Bcl2 (rabbit monoclonal IgG, Santa Cruz Biotechnology, Europe) for 12 hours, followed by incubation with secondary antibodies. Immunodetection was performed using chemiluminescence in an ImageQuant LAS camera imaging system (General Electrics). Images were analyzed by Gel-Pro 32 (Media Cybernetics Rockville, USA). GAPDH (mouse monoclonal IgG, Santa Cruz Biotechnology, Europe) was used to normalize all proteins.

\section{Nitric oxide serum metabolites}

Serum was obtained after blood centrifugation. Dosage was performed as described previously [28]. $\mathrm{NaNO}_{2}$ dilution curves were made and samples applied in duplicate. Griess reagent (100 $\left.\mu \mathrm{l}\right)$ was added to all wells. Spectrophotometry readings were performed at $540 \mathrm{~nm}$.

\section{Statistical analyses}

Variables with normal distribution were shown as means \pm standard deviation. Variables with nonnormal distribution were normalized by mathematical transforming for statistical analysis. Comparisons between groups were by two-way ANOVA. We adopted a statistical significance level of $\mathrm{p}<0.05$.

Variables that could not be normalized (water and food ingestion, left ventricular diastolic diameter, left ventricular posterior wall thickness, and superoxide dismutase activity) were analyzed by the ' $t$ ' or Mann-Whitney test. In these cases, $\mathrm{p}$ values were adjusted by Bonferroni correction and we considered statistical significance when $\mathrm{p}<0.008$ ( 0.05 divided by number of possible comparisons). 


\section{Results}

Morphological characteristics and food and water ingestion

All groups had the same mean body weight at the beginning of the experiment and weight gain was similar between groups. After doxorubicin injection, rats in groups D and DA had decreased body weight with decreased food and water ingestion (Fig. 1).

Left ventricular weight was lower in rats treated with doxorubicin than in rats that did not receive the drug; however, when left ventricular weight was normalized to body weight, rats that received doxorubicin had higher left ventricular weight (Fig. 1). Açai did not interfere with these variables.

\section{Echocardiography}

Group D had greater left ventricular systolic diameter and left atrial diameter than group C. Group DA exhibited lower left ventricular systolic diameter and left atrial diameter than group D. Regarding left ventricular function, group D exhibited less left ventricular fractional shortening than did group C. Group DA showed improvement in left ventricular fractional shortening compared with group D. These results indicate that açai supplementation was effective in improving cardiac structure and function in vivo (Table 1 ).
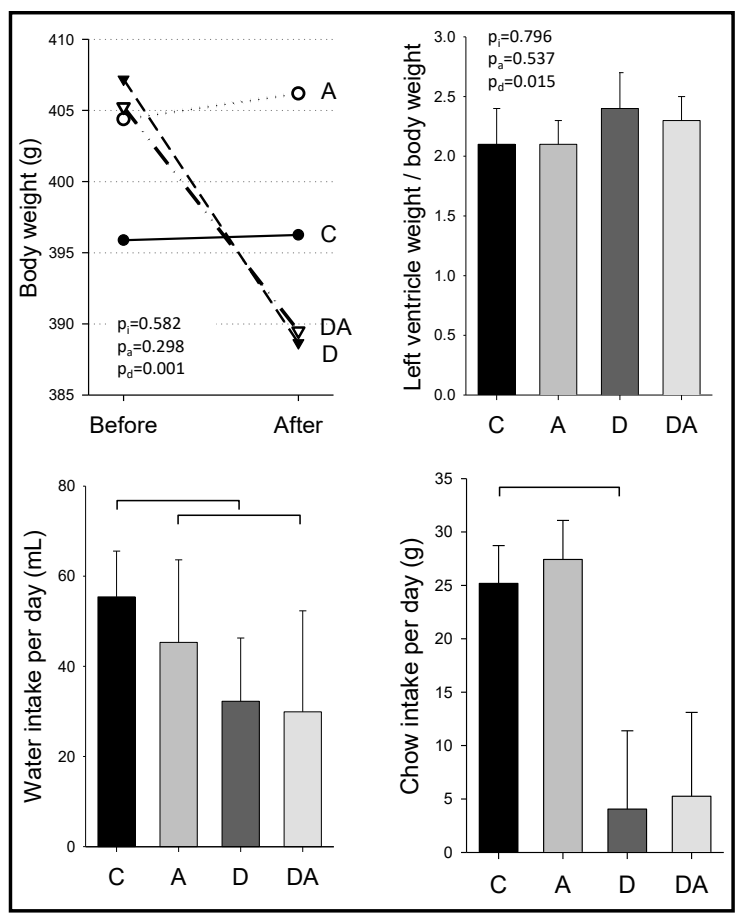

Fig. 1. Body weight and chow and water ingestion. C: control group; A: açai group; D: doxorubicin group; DA: doxorubicin + açai group. Before: body weight immediately before doxorubicin injection; After: body weight 48 hours after doxorubicin injection. Chow and water intake represent daily ingestion after doxorubicin injection. p value: two-way ANOVA. except chow and water intake comparisons. which were analyzed by Mann-Whitney test (in this situation $\mathrm{p}<0.008$ was considered significant). Brackets link two significantly different groups; pi: $p$ value for doxorubicin vs açai interaction; pa: $p$ value for açai; $p d$ : $\mathrm{p}$ value for doxorubicin.

\section{Isolated heart study}

Table 2 displays the isolated heart study results. Doxorubicin decreased maximum $+\mathrm{dP} /$ $\mathrm{dt}$, maximum $-\mathrm{dP} / \mathrm{dt}$ and maximum systolic pressure, suggesting worsening in systolic and diastolic function in vitro. We did not observe any influence from açai in these results.

\section{Apoptosis}

Regarding Bcl-2 expression, there were no differences between groups. Doxorubicin administration increased 19KDa caspase-3 expression, and açai supplementation did not change this result (Fig. 2).

\section{MMP-2 activity}

Doxorubicin administration increased both MMP-2 bands in zymography gels. Açai supplementation decreased the intensity of the lower bands both in rats that did and did not receive doxorubicin (Fig. 3). 


\section{Cellular Physiology Cell Physiol Biochem 2019;53:388-399 \\ \begin{tabular}{ll|l} 
and Biochemistry $10.33594 / 000000145$ & Published online: 13 August 2019 & $\begin{array}{l}\text { C } 2019 \text { The Author(s). Published by } \\
\text { Cell Physiol Biochem Press GmbH\&Co. KG }\end{array}$
\end{tabular} \\ Mathias et al.: Açai Attenuates Doxorubicin Cardiotoxicity}

Table 1. Morphological variables and cardiac function in vivo evaluated by Echocardiogram. C: control group; A: açai group; D: doxorubicin group; DA: doxorubicin + açai group; HR: heart rate; LVSD: left ventricle (LV) systolic diameter; LVDD: LV diastolic diameter; PW: diastolic posterior wall thickness; IVS: diastolic interventricular septum thickness; LA: left atrium diameter; FS: LV fractional shortening; E: peak velocity of early ventricular filling; A: peak velocity of transmitral flow during atrial contraction; IVRTc: isovolumetric relaxation time corrected by HR. $p$ value: two-way ANOVA, except ${ }^{\circledR}$, which were analyzed by t-test or MannWhitney test (in these cases, $p$ values were considered significant when $<0.008$ ); $p i$ : $p$ value for doxorubicin vs açai interaction; *different from C group; ${ }^{\circledR}$ different from D group

\begin{tabular}{lccccccc}
\hline Variables & $\mathrm{C}(\mathrm{n}=16)$ & $\mathrm{A}(\mathrm{n}=16)$ & $\mathrm{D}(\mathrm{n}=15)$ & $\mathrm{DA}(\mathrm{n}=16)$ & $\mathrm{p}_{\mathrm{i}}$ & $\mathrm{p}_{\text {açai }}$ & $\mathrm{p}_{\text {doxo }}$ \\
\hline HR (bpm) & $343 \pm 51$ & $326 \pm 66$ & $286 \pm 58$ & $306 \pm 60$ & 0.230 & 0.894 & 0.013 \\
LVSD (mm) & $2.81 \pm 0.46$ & $3.04 \pm 0.43$ & $3.89 \pm 0.88^{*}$ & $3.05 \pm 0.71 \&$ & 0.002 & 0.110 & 0.003 \\
LVDD (mm)@ $^{@}$ & $6.9(6.6-7.5)$ & $7.3(6.9-7.5)$ & $6.9(6.2-7.4)$ & $6.4(6.0-7.2)$ & 0.324 & 0.335 & 0.324 \\
PW (mm) & $1.5(1.5-1.7)$ & $1.5(1.5-1.8)$ & $1.5(1.5-1.5)$ & $1.5(1.5-1.5)$ & 0.766 & 0.752 & 0.502 \\
IVS (mm) & $1.5(1.5-1.8)$ & $1.8(1.5-1.8)$ & $1.8(1.5-1.8)$ & $1.8(1.7-1.8)$ & 0.415 & 0.138 & 0.520 \\
LA (mm) & $4.9 \pm 0.3$ & $5.0 \pm 0.4$ & $5.5 \pm 0.8^{*}$ & $4.9 \pm 0.5 \&$ & 0.012 & 0.054 & 0.037 \\
FS (\%) & $60 \pm 6$ & $58 \pm 4$ & $44 \pm 9^{*}$ & $54 \pm 6^{\&}$ & 0.001 & 0.014 & 0.001 \\
E/A ratio & $1.59 \pm 0.26$ & $1.6 \pm 0.25$ & $1.67 \pm 0.43$ & $1.50 \pm 0.22$ & 0.233 & 0.295 & 0.905 \\
IVRTc & $65 \pm 13$ & $66 \pm 8.5$ & $70 \pm 17$ & $71 \pm 8.7$ & 0.959 & 0.743 & 0.133 \\
\hline
\end{tabular}

Table 2. Left ventricular function in vitro evaluated by isolated heart study. C: control group; A: açai group; D: doxorubicin group; DA: doxorubicin + açai group; $\mathrm{V}_{0}$ : initial balloon volume; $+\mathrm{dP} / \mathrm{dt}$ : maximum left ventricular pressure development rate; $-\mathrm{dP} / \mathrm{dt}$ : maximum left ventricular pressure decrease rate; $\mathrm{SP}_{\max }$ : maximum systolic pressure. Values are expressed as the mean \pm standard deviation; $\mathrm{p}$ value: two-way ANOVA; pi: p value for doxorubicin vs acai interaction; ${ }^{\#}$ variable was normalized to statistical analysis

\begin{tabular}{lccccccc}
\hline Variables & $\mathrm{C}(\mathrm{n}=8)$ & $\mathrm{A}(\mathrm{n}=8)$ & $\mathrm{D}(\mathrm{n}=7)$ & $\mathrm{DA}(\mathrm{n}=8)$ & $\mathrm{p}_{\mathrm{i}}$ & $\mathrm{p}_{\text {acai }}$ & $\mathrm{p}_{\text {doxo }}$ \\
\hline $\mathrm{V}_{\mathrm{o}}(\mu \mathrm{L})$ & $85.6 \pm 36.4$ & $90.0 \pm 23.0$ & $77.1 \pm 32.9$ & $86.9 \pm 22.5$ & 0.801 & 0.508 & 0.585 \\
$+\mathrm{dP} / \mathrm{dt} \mathrm{t}^{\sharp}(\mathrm{mmHg} / \mathrm{s})$ & $2961 \pm 1066$ & $3109 \pm 978$ & $1768 \pm 434$ & $1680 \pm 554$ & 0.579 & 0.912 & $<0.001$ \\
$-\mathrm{dP} / \mathrm{dt}(\mathrm{mmHg} / \mathrm{s})$ & $2063 \pm 612$ & $2422 \pm 619$ & $1275 \pm 514$ & $1133 \pm 485$ & 0.226 & 0.596 & $<0.001$ \\
$\mathrm{SP}_{\operatorname{Max}}(\mathrm{mmHg})$ & $143 \pm 39$ & $137 \pm 29$ & $99 \pm 21$ & $90 \pm 23$ & 0.918 & 0.499 & $<0.001$ \\
\hline
\end{tabular}

\section{Oxidative stress}

Rats treated with doxorubicin exhibited higher levels of myocardial lipid hydroperoxide than not treated rats, and açai administration decreased myocardial lipid hydroperoxide levels both in rats that did and did not receive doxorubicin. Additionally, doxorubicin decreased catalase and glutathione peroxidase antioxidant enzyme activity. Açai supplementation increased catalase activity both in rats treated and not treated with doxorubicin. In addition, the DA group exhibited increased glutathione peroxidase activity that achieved values near those of group C (Table 3).

\section{Myocardial metabolism}

Doxorubicin increased phosphofructokinase and lactate dehydrogenase activity, along with decreased $\beta$-hydroxyacyl CoA dehydrogenase, pyruvate dehydrogenase and citrate synthase activity. The DA group showed greater activity of phosphofructokinase, $\beta$-hydroxyacyl CoA dehydrogenase and citrate synthase than group D. Açai administration decreased lactate dehydrogenase and increased pyruvate dehydrogenase activity both in rats that did and did not receive doxorubicin. Regarding the respiratory mitochondrial chain, doxorubicin decreased complex I, II and ATP synthase activities. Complex II activity was better in DA than D, and the DA group exhibited similar ATP synthase activity to group C (Table 4). 
Fig. 2. Apoptosis-related protein expression. Figure shows Bcl-2 and caspase 3 protein expression evaluated by Western blot. All values of protein expression were normalized by GAPDH. C: control group; A: açai group; D: doxorubicin group; DA: doxorubicin + açai group. p value: two-way ANOVA; pi: $p$ value for doxorubicin vs açai interaction; $p a: p$ value for açai; $p d$ : $p$ value for doxorubicin.

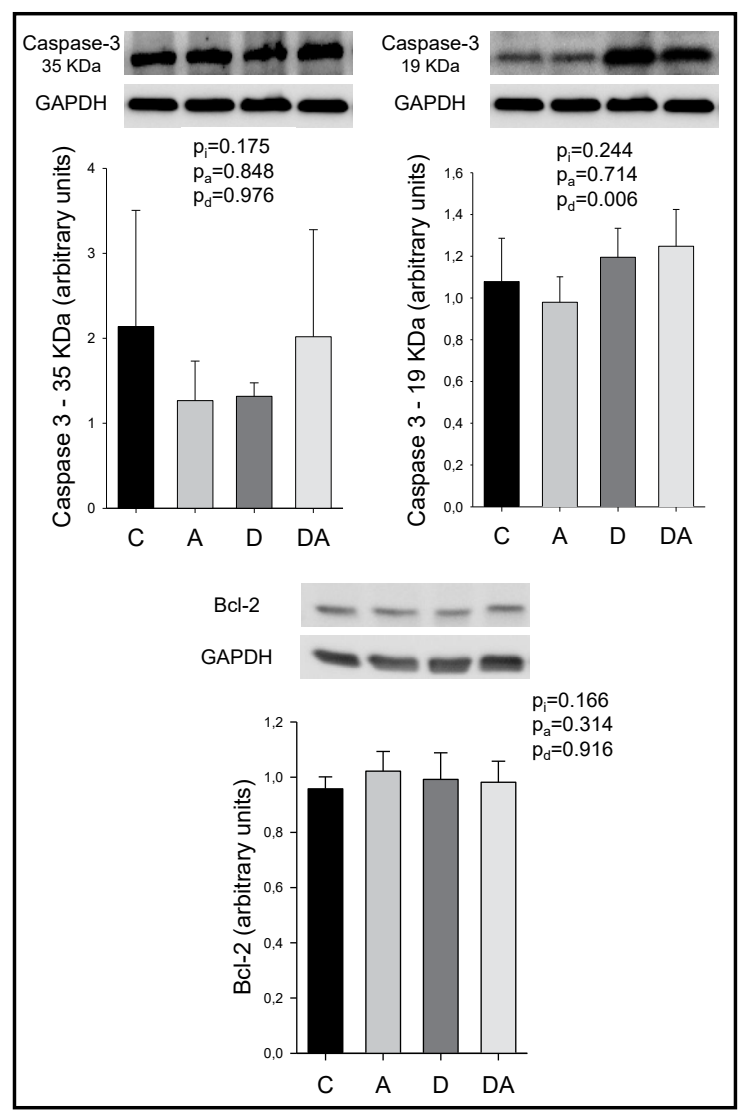

Fig. 3. Matrix metalloproteinase-2 activity. Figure shows zymography gel image. White bands represent gelatin degradation by matrix metalloproteinase (MMP)-2. C: control group; A: açai group; D: doxorubicin group; DA: doxorubicin + açai group. rMMP-2: recombinant mouse/rat MMP-2 used as positive control. $p$ value: twoway ANOVA; pi: p value for doxorubicin vs açai interaction; pa: $p$ value for açai; $p d$ : $p$ value for doxorubicin.

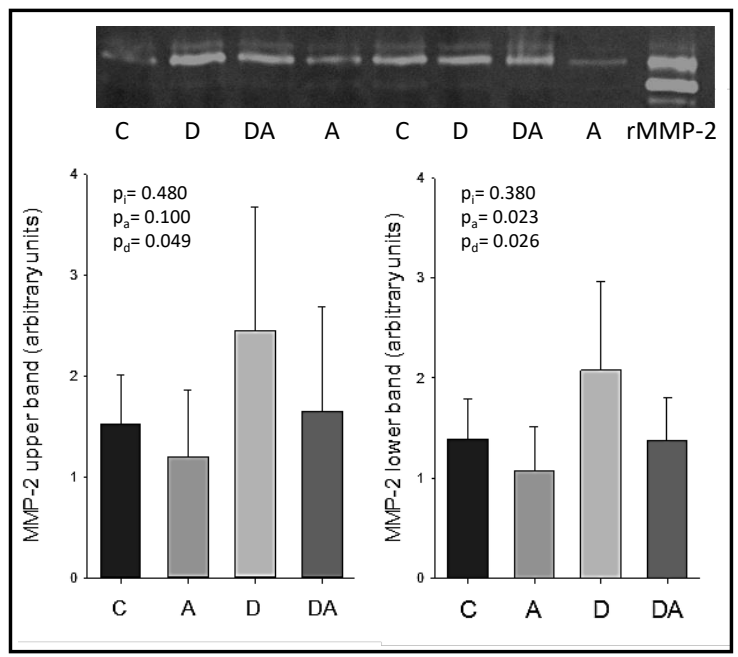

Nitric oxide metabolites

We did not observe differences in nitric oxide metabolite serum concentrations between groups (C: $10.8 \pm 6.0, A: 9.62 \pm 4.7, \mathrm{D}: 9.74 \pm 4.6$, DA: $10.9 \pm 6.7 \mathrm{nM} / \mu \mathrm{L} ; \mathrm{p}_{\text {doxo }}=0.863, \mathrm{p}_{\text {açai }}=0.771$, $\left.\mathrm{p}_{\text {interaction }}=0.536\right)$. 


\section{Cellular Physiology Cell Physiol Biochem 2019;53:388-399 \begin{tabular}{ll|l} 
and Biochemistry $10.33594 / 000000145$ & Published online: 13 August 2019 & $\begin{array}{l}\text { C } 2019 \text { The Author(s). Published by } \\
\text { Cell Physiol Biochem Press GmbH\&Co. KG }\end{array}$
\end{tabular} \\ Mathias et al.: Açai Attenuates Doxorubicin Cardiotoxicity}

Table 3. Oxidative stress marker and activity of antioxidant enzymes. C: control group; A: açai group; D: doxorubicin group; DA: doxorubicin + açai group; LH: lipid hydroperoxide; CAT: catalase; SOD superoxide dismutase; GSH-Px: glutathione peroxidase. Values are expressed as the mean \pm standard deviation or median and quartile interval (SOD). p value: two-way ANOVA, except ${ }^{\circledR}$, which was analyzed by MannWhitney test (in this situation, $p$ value was considered significant when $<0.008$ ); pi: $p$ value for doxorubicin vs acai interaction; ${ }^{*}$ different from $\mathrm{C}$ group; ${ }^{\&}$ different from D group

\begin{tabular}{|c|c|c|c|c|c|c|c|}
\hline Variables & $C(n=8)$ & $A(n=8)$ & $\mathrm{D}(\mathrm{n}=8)$ & DA $(n=8)$ & $\mathrm{p}_{\mathrm{i}}$ & $\mathrm{p}_{\text {açai }}$ & $\mathrm{p}_{\text {doxo }}$ \\
\hline $\begin{array}{l}\text { LH } \\
\text { (nmol/g tissue) }\end{array}$ & $213 \pm 40$ & $180 \pm 31$ & $321 \pm 38$ & $240 \pm 32$ & 0.068 & $<0.001$ & $<0.001$ \\
\hline $\begin{array}{l}\text { CAT } \\
(\mu \mathrm{mol} / \mathrm{g} \text { tissue })\end{array}$ & $78.4 \pm 19.2$ & $104.4 \pm 25.0$ & $42.9 \pm 10.5$ & $62.2 \pm 10.3$ & 0.596 & 0.001 & $<0.001$ \\
\hline $\begin{array}{l}\text { SOD } @ \\
\text { (nmol/mg protein) }\end{array}$ & $11.4(9.9-13.1)$ & $9.5(9.0-11.6)$ & $10.5(9.6-12.9)$ & $10.0(9.4-11.2)$ & 0.195 & 0.815 & 0.102 \\
\hline $\begin{array}{l}\text { GSH-Px } \\
\text { (nmol/mg tissue) }\end{array}$ & $75.0 \pm 8.2$ & $69.9 \pm 6.7$ & $55.2 \pm 8.1^{*}$ & $77.1 \pm 5.1 \&$ & $<0.001$ & 0.002 & 0.018 \\
\hline
\end{tabular}

Table 4. Activity of enzymes related to myocardium energy metabolism. C: control group; A: açai group; D: doxorubicin group; DA: doxorubicin + açai group. Values are expressed as the mean \pm standard deviation; p value: two-way ANOVA; pi: p value for doxorubicin vs açai interaction; *different from C group; ${ }^{\circledR}$ different from D group; ${ }^{\%}$ different from A group

\begin{tabular}{|c|c|c|c|c|c|c|c|}
\hline Variables & $C(n=8)$ & $A(n=8)$ & $D(n=8)$ & DA $(n=8)$ & $\mathrm{p}_{\mathrm{i}}$ & $\mathrm{p}_{\text {açai }}$ & $\mathrm{p}_{\text {doxo }}$ \\
\hline $\begin{array}{l}\beta \text {-hydroxyacyl-CoA- dehydrogenase } \\
\text { (nmoL/mg protein) }\end{array}$ & $31.5 \pm 5.0$ & $26.2 \pm 3.9^{*}$ & $13.0 \pm 2.8^{*}$ & $21.4 \pm 2.4 \& \%$ & $<0.001$ & 0.251 & $<0.001$ \\
\hline $\begin{array}{l}\text { Phosphofructokinase } \\
\text { (nmoL/g tissue) }\end{array}$ & $145 \pm 28.8$ & $138 \pm 19.8$ & $176 \pm 25.6^{*}$ & $133 \pm 22.7 \&$ & 0.047 & 0.008 & 0.156 \\
\hline $\begin{array}{l}\text { Lactate dehydrogenase } \\
\text { (nmoL/mg protein) }\end{array}$ & $58.3 \pm 8.5$ & $48.5 \pm 6.7$ & $111 \pm 30.3$ & $77.1 \pm 25.6$ & 0.263 & 0.002 & 0.001 \\
\hline $\begin{array}{l}\text { Pyruvate dehydrogenase } \\
\text { (nmoL/g tissue) }\end{array}$ & $267 \pm 41.4$ & $348 \pm 33.2$ & $152 \pm 34.2$ & $268 \pm 37.2$ & 0.206 & $<0.001$ & $<0.001$ \\
\hline $\begin{array}{l}\text { Citrate synthase } \\
\text { (nmol/mg protein) }\end{array}$ & $49.0 \pm 7.2$ & $42.6 \pm 5.7$ & $26.6 \pm 6.5^{*}$ & $36.3 \pm 6.5^{\&}$ & $<0.001$ & 0.150 & $<0.001$ \\
\hline $\begin{array}{l}\text { Complex I } \\
\text { (nmol/mg protein) }\end{array}$ & $13.4 \pm 4.3$ & $13.9 \pm 3.4$ & $9.1 \pm 2.5$ & $10.9 \pm 2.1$ & 0.560 & 0.308 & 0.003 \\
\hline $\begin{array}{l}\text { Complex II } \\
\text { (nmol/mg protein) }\end{array}$ & $4.8 \pm 1.1$ & $4.1 \pm 0.9$ & $1.6 \pm 0.4^{*}$ & $2.5 \pm 0.6^{\& \%}$ & 0.009 & 0.786 & $<0.001$ \\
\hline $\begin{array}{l}\text { ATP synthase } \\
\text { (nmol/mg protein) }\end{array}$ & $22.7 \pm 3.2$ & $22.4 \pm 2.9$ & $13.0 \pm 2.7^{*}$ & $23.8 \pm 3.0^{\&}$ & $<0.001$ & $<0.001$ & $<0.001$ \\
\hline
\end{tabular}

\section{Discussion}

The aim of this study was to investigate the role of açai supplementation in prevention of cardiac dysfunction and biochemical changes in acute doxorubicin-induced cardiotoxicity. Our results showed that doxorubicin administration was able to induce cardiotoxicity, with morphological changes, impairment of left ventricular function, increases in MMP-2, oxidative stress and changes in cardiac metabolism compatible with pathological conditions. When açai was administered in tandem, we observed improvements in left ventricular function and cardiac metabolism and decreases in oxidative stress and MMP-2.

Açai is composed of proteins, fibers, minerals, unsaturated fatty acids and high levels of high antioxidant phenolic compounds, such as anthocyanin [15]. Anthocyanin may be absorbed as an intact molecule in the stomach or small bowel, as these intact molecules have been found in plasma and urine [29]. Rats ate $25 \mathrm{~g}$ of the chow açai mix per day, which is equivalent to $1.25 \mathrm{~g}$ of açai pulp per day. This amount is equivalent to $39 \mathrm{~g}$ of açai for humans (2.5 tablespoons per day) [30].

Doxorubicin can induce generalized side effects, including alopecia, neutropenia, nausea, vomiting and decreased appetite [3]. Indeed, we observed decreased food and water ingestion, followed by decreases in body weight in rats that received doxorubicin. Reduced 


\section{Cellular Physiology Cell Physiol Biochem 2019;53:388-399 \\ \begin{tabular}{ll|l} 
and Biochemistry & $\begin{array}{l}\text { DOl: } 10.33594 / 000000145 \\
\text { Published online: } 13 \text { August } 2019\end{array}$ & $\begin{array}{l}\text { C } 2019 \text { The Author(s). Published by } \\
\text { Cell Physiol Biochem Press GmbH\&Co. KG }\end{array}$
\end{tabular} \\ Mathias et al.: Açai Attenuates Doxorubicin Cardiotoxicity}

body weight was probably due to decreases in intravascular volume as the period was very short (48 hours) for decreases in body mass. As a result of intravascular volume depletion, rats could have tissue hypoperfusion. To maintain organic perfusion, the rats may have had peripheral vasoconstriction and increased afterload. In hearts with dysfunction, such as hearts with acute cardiotoxicity, increased afterload could contribute to cardiac function impairment.

Rats that received doxorubicin showed worse systolic and diastolic left ventricular function on echocardiography than rats that did not receive doxorubicin. The same results were observed in terms of cardiac function evaluation in vitro (isolated heart study), where rats that received doxorubicin exhibited lower $+\mathrm{dP} / \mathrm{dt}$ (that represents systolic function) and lower $-\mathrm{dP} / \mathrm{dt}$ (that represents diastolic function). When açai was also administered, we observed improved left ventricular function in vivo, but not in vitro. We believe that these differences could result from vasodilatation induced by açai administration [31], as the afterload component was absent in the isolated heart study.

Doxorubicin could induce vasoconstriction mediated by several mechanisms, including the renin-angiotensin-aldosterone system and adrenergic stimuli [7]. Another mechanism involved in doxorubicin-induced vasoconstriction is nitric oxide mediation [32] and açai could affect the nitric oxide system [33-35]. To investigate the vasodilator effect of açai, we evaluated nitric oxide metabolite serum levels. However, results were similar between groups.

Increases in oxidative stress are frequently implicated in the pathophysiology of doxorubicin-induced cardiotoxicity. The myocardium is more susceptible to oxidative damage than other organs for several reasons. First, the heart has lower levels of catalase and superoxide dismutase [36]; second, glutathione peroxidase is quickly inactivated by doxorubicin in the myocardium [36]; third, the heart is rich in mitochondria, an important source of reactive oxygen species production and a target for doxorubicin action [32]. Indeed, in animals that received doxorubicin we observed decreased glutathione peroxidase and catalase activities and increased myocardial lipid hydroperoxide, a cellular lipid damage marker. Lipid peroxidation disrupts the cell barrier, cellular membrane channels and membrane pumps, which contributes to worsening cardiac function. Açai administration reduced lipid hydroperoxide in both the A and DA groups, thus reinforcing its antioxidant properties.

A pro-oxidative environment is one of the most potent stimuli for MMP-2 activation, including intracellular activation, where MMP-2 has a high affinity for contractile proteins and could contribute to myocardium dysfunction [11]. MMP activation is essential for the remodeling process. Increased MMP-2 gene expression and activation are early events in cardiotoxicity and follow heart dilatation $[5,6,12,13]$. Indeed, our results showed higher MMP-2 activity in doxorubicin-treated animals combined with increases in oxidative stress and increases in cardiac left chambers. It could be a potential target for preventing dilated cardiomyopathy induced by doxorubicin. In our study, açai supplementation reduced MMP2 activation and it was accompanied by decreased left ventricle systolic and left atrium diameters.

There are several mechanisms that can generate reactive species, one of which is the mitochondrial phosphorylative respiratory chain. A previous study showed that doxorubicin interfered with all mitochondrial enzymatic complex activities [37]. However, another study showed that the effect of doxorubicin on mitochondrial complex activity was not homogenous, with more intense effects in complex III and IV, lower intensity in complex I and no effect in complex II [38]. We observed that doxorubicin decreased complex I, II and ATP synthase activity in rats. Açai attenuated mitochondrial dysfunction because of increased ATP synthase activity near group C levels, and considerably improved complex II activity. Additionally, açai supplementation increased citrate synthase activity, which could have improved the Krebs cycle function. By increasing ATP synthase activity, açai may have collaborated in increasing ATP generation. 


\section{Cellular Physiology Cell Physiol Biochem 2019;53:388-399

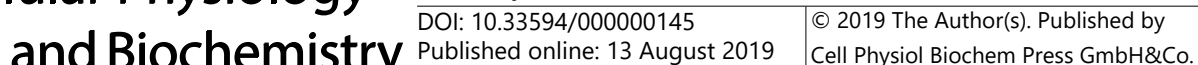 \\ Mathias et al.: Açai Attenuates Doxorubicin Cardiotoxicity}

In physiological situations, fatty acids are the main substrate for energy generation in the myocardium. However, in pathologic situations, the myocardium starts to use mainly glucose, as fatty acids require more energy to be metabolized than glucose [39]. Acutely, it is a protective strategy for the myocardium, but chronically, the accumulation of fatty acids inside myocytes could be damaging [40]. In our study, doxorubicin induced changes compatible with pathological situations. We observed increased activity in enzymes related to the glucose metabolism and decreased activity in $\beta$-hydroxyacyl CoA dehydrogenase enzyme related to fatty acid metabolism. When açai was also administered, we observed that enzyme activity related to the energetic metabolism was maintained close to normal.

Despite the importance of apoptosis in the doxorubicin antitumor effect, apoptosis can also contribute to cardiotoxicity. Doxorubicin could interfere with p53 and p38 regulation, PI3K/Akt pathway inhibition, activated caspases and deregulated Bcl-2 and Bax protein expression [32, 41-44]. In contrast to previous studies showing that doxorubicin decreased Bcl-2 expression [43,44], we did not observe differences in Bcl-2 expression between groups. Perhaps the Bcl-2/Bax ratio is more important than Bcl-2 expression alone in this experimental model [45]. As expected, our study showed doxorubicin-induced increases in caspase-3 protein expression, suggesting that apoptosis is an important mechanism in doxorubicin-induced cardiotoxicity, but açai had no effect on this injury mechanism.

It is important to emphasize that our experimental model utilized a high single dose of doxorubicin and did not exactly reproducing doxorubicin administration in humans. However, this model is fast, less expensive and reduces animal suffering. In addition, chronic cardiotoxicity shares pathophysiological mechanisms with acute cardiotoxicity and is a good model for studying potential substances and strategies that can prevent cardiotoxicity. Despite our encouraging results, clinical studies are necessary to determine the role of açai in this severe complication.

\section{Conclusion}

Acute doxorubicin administration induced in vivo and in vitro left ventricular dysfunction, increased oxidative stress, caspase- 3 protein expression, MMP-2 activation, and induced changes in myocardium energy metabolism compatible with pathological conditions. Açai supplementation attenuated cardiotoxicity with improved cardiac function in vivo, decreased oxidative damage and MMP-2 activation, and modulated myocardial metabolism changes including improvement in the mitochondrial phosphorylative respiratory chain. Açai can therefore potentially prevent or attenuate doxorubicin-induced cardiotoxicity.

\section{Acknowledgements}

This work was supported by the Conselho Nacional de Desenvolvimento Científico e Tecnológico - CNPq (process number 400970/2016-3), Fundação de Amparo à Pesquisa do Estado de São Paulo - FAPESP (process number 2018/03381-9), and Coordenação de Aperfeiçoamento de Pessoal de Nível Superior - CAPES.

The authors are grateful to Colin Edward Knaggs for English editing.

\section{Disclosure Statement}

The authors declare that they have no competing interests. 


\section{Cellular Physiology Cell Physiol Biochem 2019;53:388-399 \begin{tabular}{ll|l|l|}
\hline DOI: 10.33594/000000145 & (C)19 The Author(s). Published by
\end{tabular} and Biochemistry Published online: 13 August 2019 Cell Physiol Biochem Press GmbH\&Co. KG \\ Mathias et al.: Açai Attenuates Doxorubicin Cardiotoxicity}

\section{References}

1 Volkova M, Russell R, 3rd: Anthracycline cardiotoxicity: prevalence, pathogenesis and treatment. Curr Cardiol Rev 2011;7:214-220.

2 Bristow MR, Thompson PD, Martin RP, Mason JW, Billingham ME, Harrison DC: Early anthracycline cardiotoxicity. Am J Med 1978;65:823-832.

3 Wojtacki J, Lewicka-Nowak E, Lesniewski-Kmak K: Anthracycline-induced cardiotoxicity: clinical course, risk factors, pathogenesis, detection and prevention-review of the literature. Med Sci Monit 2000;6:411420 .

4 Toko H, Oka T, Zou Y, Sakamoto M, Mizukami M, Sano M, Yamamoto R, Sugaya T, Komuro I: Angiotensin II type 1a receptor mediates doxorubicin-induced cardiomyopathy. Hypertens Res 2002;25:597-603.

5 Polegato BF, Minicucci MF, Azevedo PS, Carvalho RF, Chiuso-Minicucci F, Pereira EJ, Paiva SA, Zornoff LA, Okoshi MP, Matsubara BB, Matsubara LS: Acute Doxorubicin-Induced Cardiotoxicity is Associated with Matrix Metalloproteinase-2 Alterations in Rats. Cell Physiol Biochem 2015;35:1924-1933.

6 Carvalho PB, Gonçalves AF, Alegre PH, Azevedo PS, Roscani MG, Bergamasco CM, Modesto PN, Fernandes AA, Minicucci MF, Paiva SA, Antonio L, Zornoff M, Polegato BF: Pamidronate Attenuates Oxidative Stress and Energetic Metabolism Changes but Worsens Functional Outcomes in Acute Doxorubicin-Induced Cardiotoxicity in Rats. Cell Physiol Biochem 2016;40:431-442.

7 Renu K, V GA, P BT, Arunachalam S: Molecular mechanism of doxorubicin-induced cardiomyopathy - An update. Eur J Pharmacol 2018;818:241-253.

8 Vejpongsa P, Yeh ET: Prevention of anthracycline-induced cardiotoxicity: challenges and opportunities. J Am Coll Cardiol 2014;64:938-945.

9 Sawyer DB: Anthracyclines and heart failure. N Engl J Med 2013;368:1154-1156.

10 Zhang S, Liu X, Bawa-Khalfe T, Lu LS, Lyu YL, Liu LF, Yeh ET: Identification of the molecular basis of doxorubicin-induced cardiotoxicity. Nat Med 2012;18:1639-1642.

11 Kandasamy AD, Chow AK, Ali MA, Schulz R: Matrix metalloproteinase-2 and myocardial oxidative stress injury: beyond the matrix. Cardiovasc Res 2010;85:413-423.

12 Kizaki K, Ito R, Okada M, Yoshioka K, Uchide T, Temma K, Mutoh K, Uechi M, Hara Y: Enhanced gene expression of myocardial matrix metalloproteinases 2 and 9 after acute treatment with doxorubicin in mice. Pharmacol Res 2006;53:341-346.

13 Bai P, Mabley JG, Liaudet L, Virag L, Szabo C, Pacher P: Matrix metalloproteinase activation is an early event in doxorubicin-induced cardiotoxicity. Oncol Rep 2004;11:505-508.

14 Octavia Y, Tocchetti CG, Gabrielson KL, Janssens S, Crijns HJ, Moens AL: Doxorubicin-induced cardiomyopathy: from molecular mechanisms to therapeutic strategies. J Mol Cell Cardiol 2012;52:12131225.

15 Yamaguchi KK, Pereira LF, Lamarao CV, Lima ES, da Veiga-Junior VF: Amazon acai: chemistry and biological activities: a review. Food Chem 2015;179:137-151.

16 Schauss AG, Wu X, Prior RL, Ou B, Huang D, Owens J, Agarwal A, Jensen GS, Hart AN, Shanbrom E: Antioxidant capacity and other bioactivities of the freeze-dried Amazonian palm berry, Euterpe oleraceae mart. (acai). J Agric Food Chem 2006;54:8604-8610.

17 Wu X, Schauss AG: Mitigation of inflammation with foods. J Agric Food Chem 2012;60:6703-6717.

18 Fragoso MF, Prado MG, Barbosa L, Rocha NS, Barbisan LF: Inhibition of mouse urinary bladder carcinogenesis by acai fruit (Euterpe oleraceae Martius) intake. Plant Foods Hum Nutr 2012;67:235-241.

19 Fragoso MF, Romualdo GR, Ribeiro DA, Barbisan LF: Acai (Euterpe oleracea Mart.) feeding attenuates dimethylhydrazine-induced rat colon carcinogenesis. Food Chem Toxicol 2013;58:68-76.

20 Rocha AP, Carvalho LC, Sousa MA, Madeira SV, Sousa PJ, Tano T, Schini-Kerth VB, Resende AC, Soares de Moura R: Endothelium-dependent vasodilator effect of Euterpe oleracea Mart. (Acai) extracts in mesenteric vascular bed of the rat. Vascul Pharmacol 2007;46:97-104.

21 Ribeiro JC, Antunes LM, Aissa AF, Darin JD, De Rosso VV, Mercadante AZ, Bianchi M de L: Evaluation of the genotoxic and antigenotoxic effects after acute and subacute treatments with acai pulp (Euterpe oleracea Mart.) on mice using the erythrocytes micronucleus test and the comet assay. Mutat Res 2010;695:22-28.

22 Andreadou I, Sigala F, Iliodromitis EK, Papaefthimiou M, Sigalas C, Aligiannis N, Savvari P, Gorgoulis V, Papalabros E, Kremastinos DT: Acute doxorubicin cardiotoxicity is successfully treated with the phytochemical oleuropein through suppression of oxidative and nitrosative stress. J Mol Cell Cardiol 2007;42:549-558. 


\section{Cellular Physiology Cell Physiol Biochem 2019;53:388-399

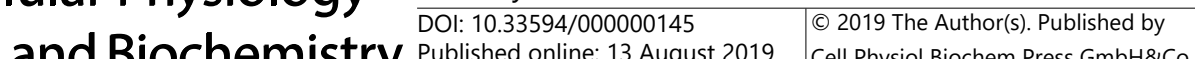 and BiOChemistry Published online: 13 August 2019 Cell Physiol Biochem Press GmbH\&Co. KG \\ Mathias et al.: Açai Attenuates Doxorubicin Cardiotoxicity}

23 Jiang ZY, Woollard AC, Wolff SP: Lipid hydroperoxide measurement by oxidation of Fe2+ in the presence of xylenol orange. Comparison with the TBA assay and an iodometric method. Lipids 1991;26:853-856.

24 Nakamura A, Minakami S: Synthesis of catalase in liver slices from aminotriazole-pretreated rats. J Biochem 1974;75:1373-1375.

25 Ewing JF, Janero DR: Microplate superoxide dismutase assay employing a nonenzymatic superoxide generator. Anal Biochem 1995;232:243-248.

26 Bass A, Brdiczka D, Eyer P, Hofer S, Pette D: Metabolic differentiation of distinct muscle types at the level of enzymatic organization. Eur J Biochem 1969;10:198-206.

27 Cassina A, Radi R: Differential inhibitory action of nitric oxide and peroxynitrite on mitochondrial electron transport. Arch Biochem Biophys 1996;328:309-316.

28 Green LC, Wagner DA, Glogowski J, Skipper PL, Wishnok JS, Tannenbaum SR: Analysis of nitrate, nitrite, and [15N]nitrate in biological fluids. Anal Biochem 1982;126:131-138.

29 Passamonti S, Vrhovsek U, Vanzo A, Mattivi F: The stomach as a site for anthocyanins absorption from food. FEBS Lett 2003;544:210-213.

30 Reagan-Shaw S, Nihal M, Ahmad N: Dose translation from animal to human studies revisited. FASEB J 2008;22:659-661.

31 de Bem GF, da Costa CA, de Oliveira PR, Cordeiro VS, Santos IB, de Carvalho LC, Souza MA, Ognibene DT, Daleprane JB, Sousa PJ, Resende AC, de Moura RS: Protective effect of Euterpe oleracea Mart (acai) extract on programmed changes in the adult rat offspring caused by maternal protein restriction during pregnancy. J Pharm Pharmacol 2014;66:1328-1338.

32 Ghigo A, Li M, Hirsch E: New signal transduction paradigms in anthracycline-induced cardiotoxicity. Biochim Biophys Acta 2016;1863:1916-1925.

33 Matheus ME, de Oliveira Fernandes SB, Silveira CS, Rodrigues VP, de Sousa Menezes F, Fernandes PD: Inhibitory effects of Euterpe oleracea Mart. on nitric oxide production and iNOS expression. J Ethnopharmacol 2006;107:291-296.

34 Machado DE, Rodrigues-Baptista KC, Alessandra-Perini J, Soares de Moura R, Santos TA, Pereira KG, Marinho da Silva Y, Souza PJ, Nasciutti LE, Perini JA: Euterpe oleracea Extract (Acai) Is a Promising Novel Pharmacological Therapeutic Treatment for Experimental Endometriosis. PLoS One 2016;11:e0166059.

35 de Moura RS, Resende AC: Cardiovascular and Metabolic Effects of Acai, an Amazon Plant. J Cardiovasc Pharmacol 2016;68:19-26.

36 Minotti G, Menna P, Salvatorelli E, Cairo G, Gianni L: Anthracyclines: molecular advances and pharmacologic developments in antitumor activity and cardiotoxicity. Pharmacol Rev 2004;56:185-229.

37 Zhang Y, Chen L, Li F, Wang H, Yao Y, Shu J, Ying MZ: Cryptotanshinone protects against adriamycin-induced mitochondrial dysfunction in cardiomyocytes. Pharm Biol 2016;54:237-242.

38 Tokarska-Schlattner M, Zaugg M, Zuppinger C, Wallimann T, Schlattner U: New insights into doxorubicininduced cardiotoxicity: the critical role of cellular energetics. J Mol Cell Cardiol 2006;41:389-405.

39 Azevedo PS, Minicucci MF, Santos PP, Paiva SA, Zornoff LA: Energy metabolism in cardiac remodeling and heart failure. Cardiol Rev 2013;21:135-140.

40 Santos PP, Oliveira F, Ferreira VC, Polegato BF, Roscani MG, Fernandes AA, Modesto P, Rafacho BP, Zanati SG, Di Lorenzo A, Matsubara LS, Paiva SA, Zornoff LA, Minicucci MF, Azevedo PS: The role of lipotoxicity in smoke cardiomyopathy. PLoS One 2014;9:e113739.

41 Shaker RA, Abboud SH, Assad HC, Hadi N: Enoxaparin attenuates doxorubicin induced cardiotoxicity in rats via interfering with oxidative stress, inflammation and apoptosis. BMC Pharmacol Toxicol 2018;19:3.

42 Zhang YY, Yi M, Huang YP: Oxymatrine Ameliorates Doxorubicin-Induced Cardiotoxicity in Rats. Cell Physiol Biochem 2017;43:626-635.

43 Hajra S, Patra AR, Basu A, Bhattacharya S: Prevention of doxorubicin (DOX)-induced genotoxicity and cardiotoxicity: Effect of plant derived small molecule indole-3-carbinol (I3C) on oxidative stress and inflammation. Biomed Pharmacother 2018;101:228-243.

44 Johnson R, Shabalala S, Louw J, Kappo AP, Muller CJF: Aspalathin Reverts Doxorubicin-Induced Cardiotoxicity through Increased Autophagy and Decreased Expression of p53/mT0R/p62 Signaling. Molecules 2017;22:1589.

45 Childs AC, Phaneuf SL, Dirks AJ, Phillips T, Leeuwenburgh C: Doxorubicin treatment in vivo causes cytochrome $\mathrm{C}$ release and cardiomyocyte apoptosis, as well as increased mitochondrial efficiency, superoxide dismutase activity, and Bcl-2:Bax ratio. Cancer Res 2002;62:4592-4598. 